\title{
The Implementation of Extended Examination Duration for Students With ADHD in Higher Education
}

Journal of Attention Disorders $1-13$

(C) The Author(s) 2018

Article reuse guidelines:

sagepub.com/journals-permissions DOI: $10.1177 / 1087054718787879$

journals.sagepub.com/home/jad

(S)SAGE

\author{
Dorien Jansen', Katja Petry', Steven W. Evans², Ilse Noens', and Dieter Baeyens'
}

\begin{abstract}
Objective: Recently, research indicated that extended examination duration was perceived as effective by students with ADHD. However, the objective effectiveness of this accommodation has not been researched extensively. This study addresses this gap in literature.

Method: A total of 30 students with ADHD and 30 matched typically developing controls (TDC) participated in a simulation of a real-life examination. They filled in three parallel versions of a paper-and-pencil test in three time conditions: I hr (+0\%), I hr 20 min (+33\%), and I hr 30 min (+50\%).

Results: When granted extended examination duration, students with ADHD and TDC use extra time but their performance does not increase. In addition, test-taking strategies were altered to a limited extent, and strategies that are perceived as effective (e.g., marking key words) were rarely used by the students.

Conclusion: It is concluded that extended examination duration is not objectively effective in an experimental design. Limitations and guidelines for future research are formulated.
\end{abstract}

\section{Keywords}

reasonable accommodations, effectiveness, higher education, extended examination duration, ADHD

\section{Background}

ADHD is classified as a neurodevelopmental disorder and is characterized in the Diagnostic and Statistical Manual of Mental Disorders (5th ed.; DSM-5; American Psychiatric Association [APA], 2013) as a stable pattern of impairing symptoms of inattention, hyperactivity, and impulsivity. These specific symptoms emerge in all aspects of daily life and in education in particular. In the past decades, there has been an increase in the number of students with ADHD enrolling in higher education (e.g., DuPaul, Weyandt, O'Dell, \& Varejao, 2009). Approximately $2 \%$ to $8 \%$ of all students in higher education are diagnosed with ADHD (e.g., DuPaul et al., 2009). Apart from students with learning disabilities, the group of students with a psychiatric disorder, including students with ADHD, is the largest group of students with a disability enrolling in higher education (University of Leuven, 2015; Weyandt \& DuPaul, 2006).

When looking at the participation and success rate of students with ADHD in higher education, it becomes clear that these students are less likely to attend higher education in comparison with typically developing controls (TDC; e.g., DuPaul et al., 2009; Kuriyan et al., 2013). In addition, previous research has shown that if students with ADHD do transfer to higher education, they are more likely to have lower test scores, to repeat classes, and to drop out of higher education without a degree compared with TDC (e.g., Barkley, Fischer, Smallish, \& Fletcher, 2006; DuPaul et al., 2009; Kuriyan et al., 2013). This academic underperformance can be the result of various functioning and participation problems students with ADHD experience in higher education. For example, previous research indicates that, as a group, students with ADHD experience more problems with attention (e.g., sustaining attention, daydreaming), executive functioning (e.g., planning and organizing, prioritizing), study skills (e.g., completing tasks), and social functioning (e.g., Barkley \& Murphy, 2011; Emmers, Jansen, Petry, van der Oord, \& Baeyens, 2017; Jansen et al., 2017; Sobanski et al., 2008; Weyandt et al., 2013).

To cope with these functioning and participation problems, students with ADHD are in need of adjustments in higher education. Since the ratification of the United Nations

\footnotetext{
'University of Leuven, Leuven, Belgium

${ }^{2}$ Ohio University, Athens, USA

Corresponding Author:

Dorien Jansen, Faculty of Psychology and Educational Sciences,

University of Leuven, Leopold Vanderkelenstraat 32, box 3765,

3000 Leuven, Belgium.

Email: dorien.jansen@ppw.kuleuven.be
} 
(UN; 2006) Convention on the Rights of Persons with Disabilities, institutions of higher education are offering reasonable accommodations to students with a disability, including students with ADHD. Reasonable accommodations are expected to neutralize the negative effect of the environment on the functioning and participation of students with a disability in higher education (UN, 2006). It can be implied by this action that the UN Convention assumes that reasonable accommodations only have a positive effect on the performance of students with a disability. Consequently, reasonable accommodations may not lead to an increase of performance of TDC (Sireci, Scarpati, \& Li, 2005). This theoretical assumption is referred to as the interaction hypothesis (Sireci et al., 2005). Nevertheless, previous research, mostly on students with learning disabilities or students in secondary education, suggests that the performance of TDC is also influenced by the implementation of reasonable accommodations (e.g., Meloy, Deville, \& Frisbie, 2002; Schulte, Elliott, $\&$ Kratochwill, 2001). Reasonable accommodations are only effective and justified (i.e., do not lead to an unfair advantage) if students with a disability benefit significantly more than TDC. Sireci and colleagues (2005) refer to this theory as the differential boost hypothesis. The differential boost hypothesis is incorporated in the formal definition of reasonable accommodations, formulated by Harrison and colleagues (Harrison, Bunford, Evans, \& Owens, 2013):

reasonable accommodations are changes to practices in schools that hold a student to the same standard as students without disabilities, but provide more benefit to students with a disability (i.e. differential boost) to mediate the impact of the disability on access to the general education curriculum. (p. 6)

However, it remains unclear which reasonable accommodations should be selected and how these accommodations should be implemented to be effective and justified in dealing with specific functioning and participation problems of students with a disability. First, research has previously mentioned that student counselors have to take into account both personal and environmental characteristics when offering reasonable accommodations (Kettler, 2012). Nonetheless, this assumption was not investigated further. In addition, the literature is still indecisive about which reasonable accommodations are effective in dealing with functioning and participation problems of specific groups of students with a disability because the objective and subjective (or perceived) effect of reasonable accommodations on the performance of students with a disability in higher education has not been extensively researched. Second, guidelines regarding the implementation of reasonable accommodations are currently not based on scientific research (Smith, 2007). This results in a variety of implementation procedures for reasonable accommodations such as extended examination duration.
Specifically for students with ADHD, the literature regarding the use and effectiveness of reasonable accommodations is scarce. Researchers have already demonstrated that extended examination duration is the most used reasonable accommodation by students with ADHD in comparison with other reasonable accommodations (e.g., Jansen et al., 2017; Kettler, 2012). On one hand, students with ADHD perceive extended examination duration as effective (subjectively) in dealing with their specific functioning and participation problems (Jansen et al., 2017). On the other hand, research examining the objective effectiveness of extended examination duration classifies this reasonable accommodation as nonjustified and ineffective because both students with and without a disability benefit evenly when granted the reasonable accommodation (e.g., Lovett, 2010; Pariseau, Pelham, Fabiano, Massetti, \& Hart, 2010). However, the existing literature regarding the objective effectiveness of extended examination has important limitations. The majority of existing research investigated extended examination duration in primary or secondary education and, due to the developmental trajectory of youth with many disorders, it is unclear whether these results can be transferred to a context of higher education. Also, in many studies investigating the effectiveness of extended examination duration, students with ADHD are not included or are part of a larger group of students with disabilities. The results generated in these studies are not ADHDspecific and may not be transferable to this target group.

Recently, one study has focused on the objective effectiveness of extended examination duration for students with ADHD in higher education. Miller and colleagues (Miller, Lewandowski, \& Antshel, 2015) investigated the potential increase in performance of students with a community-practitioner-assigned diagnosis of ADHD and those without a disability when given extra time to complete a reading test. The participating students were given a reading test, which they had to complete. First, students received $15 \mathrm{~min}$ to complete the reading test. After the standard time, students changed the color of their pen and worked an additional 7 $\mathrm{min}$ and $30 \mathrm{~s}$. Finally, again after switching the color of their pen, students received another $7 \mathrm{~min}$ and $30 \mathrm{~s}$ extra time. The results show that the test scores of students with ADHD do not increase significantly more than the performance of TDC, which indicates that the criteria explicated in the differential boost hypothesis are not met. The authors conclude that both the students with ADHD and TDC benefit when extended examination duration is granted and that extended examination duration is not an appropriate accommodation for students with ADHD. Thus, the extra time did not specifically address impairment uniquely associated with that disorder. Nevertheless, there are some important limitations that should be kept in mind. First, Miller and colleagues (2015) acknowledged that the test period might be too short to evoke attentional and executive functioning problems. 
Second, only one competence, namely reading, was tested during their examination. It is unclear whether the results of this study can be transferred to tests examining different competences such as arithmetic or reasoning skills. Third, the diagnosis of the students with ADHD and potential cooccurring learning disorders were not validated within the research protocol, raising questions about the validity of the diagnosis. Finally, the students had started the test with the knowledge that they are offered extended time. It is possible that this design influences the approach of the students participating in the study. For example, if students knew from the start that they were receiving 15 min extra time, they could have taken this into account when planning their examination. This has an impact on the ecological validity of the experiment.

Next to the effectiveness and justifiability of reasonable accommodations described above, it is also important to consider how students with ADHD use the extra time. Using this extra time wisely, for example, by altering test-taking strategies, can increase the effectiveness of the reasonable accommodation. Research points out that students with ADHD do not differ from a control group when looking at the selection of test-taking strategies during high-stakes examinations (Lewandowski, Hendricks, \& Gordon, 2015). Lewandowski and his colleagues (2015) have indicated that the students with ADHD make more errors, but attempt the same number of items, work at the same speed, and use the same test-taking strategies in comparison with a control group. Finally, Elliott and Marquart (2003) have shown that students with a disability are more motivated when receiving extended time on an examination, but do not choose to work at a slower pace when offered the accommodation.

In the current study, we examined the effectiveness of extended examination duration and the test-taking strategies of students with ADHD in higher education in an experimental design that addresses some of the limitations of previous research. Specifically, we validated the diagnosis of ADHD among the participants, extended the testing session to provide a greater challenge to the ability of those with ADHD to sustain attention, examined academic abilities beyond reading, and completed the testing in a setting that resembles a naturalistic examination situation, for example, by motivating students by offering an extra incentive to the best performing students. Also, three TDC fulfilled the role of actor in each experimental time slot to increase the correspondence to a real-life examination. These actors received a guideline, which was based on observations of naturalistic examination situations. This guideline contained manipulations they had to undertake at a predetermined time, for example, dropping a pencil or asking the teacher a question when she entered. In total, three research questions were examined in this study. First, we investigated whether the students with ADHD and TDC use the extra time when it is provided. We expected that all students will take longer for a test when granted extended time. Previous research only focused on the increase in performance of students with ADHD rather than investigating whether TDC students also used the extra time granted. Second, we examined whether the performance of the students with ADHD increased more than the test scores of TDC students when both groups were offered extended examination duration. The literature suggests that the test scores of both groups of students will increase when receiving extended examination duration and that the increase for students with ADHD is equivalent to the increase of scores for TDC (Miller et al., 2015). We hypothesized that both the students with ADHD and TDC would benefit from extended examination duration. In addition, if extended time meets the criterion for an accommodation of differential boost, then we assumed that the test scores of students with ADHD will increase more compared with TDC. Third, we explored if students with ADHD and TDC alter their test-taking strategies when receiving extended time for an examination. Based on previous research, it was expected that both groups of students use the same test-taking strategies and will alter their test-taking strategies similarly when receiving extended examination duration (Elliott \& Marquart, 2003; Lewandowski et al., 2015).

\section{Method}

\section{Participants}

Students with ADHD and TDC were recruited to participate from various institutions of higher education in Flanders through the student counselors in these institutions. Student counselors were asked to send an information letter explaining the design, goals, and other specific details (e.g., date, location) of the study to students with ADHD they were counseling. In addition, specific professional organizations related to addressing the needs of individuals with ADHD in Flanders were asked to distribute the information through their website. TDC were recruited via social media, electronic learning platforms of various institutions of higher education, and during lectures. If TDC and students with ADHD were willing to participate, they read and signed the informed consent and completed two self-constructed questionnaires and the ADHD rating scale (ARS; Kooij et al., 2005). The study was approved by the Social and Societal Ethics Committee of University Leuven.

TDC were eligible to participate when (a) they were between 18 and 25 years old, (b) they were enrolled in an institution of higher education during their participation in this study, (c) they reported no known disabilities, and (d) no ADHD diagnosis or psychiatric disabilities were revealed by the use of a screening questionnaire. In total, 116 TDC were included in the experimental study. From the 116 TDC, 41 students participated in the experiment as actors to 
Table I. Mean Scores on the ARS and Demographic Characteristics of the Participating Students With ADHD and TDC.

\begin{tabular}{lrrr}
\hline & ADHD $(n=30)$ & TDC $(n=30)$ & Test statistic \\
\hline Mean score on Childhood inattention (SD) & $22.77(6.44)$ & $7.13(6.21)$ & $t(58)=9.57, p<.001$ \\
Mean score on Childhood hyperactivity/impulsivity (SD) & $21.87(7.67)$ & $7.40(5.73)$ & $t(58)=8.27, p<.001$ \\
Mean score on Adult inattention (SD) & $18.27(5.37)$ & $6.00(3.90)$ & $t(58)=10.13, p<.001$ \\
Mean score on Adult hyperactivity/impulsivity (SD) & $17.37(5.85)$ & $6.77(4.92)$ & $t(58)=7.59, p<.001$ \\
Sex (males, \%) & $10(33.3)$ & $10(33.3)$ & $\chi^{2}(1)=.00, p>.05$ \\
Mean age (SD) & $21.67(1.97)$ & $21.23(1.78)$ & $t(58)=.90, p>.05$ \\
Type of educational program (academic, \%) & $21(70.0)$ & $23(76.7)$ & $\chi^{2}(1)=.34, p>.05$ \\
Group (\%) & & \\
$\quad$ Humanities and social sciences & $14(46.7)$ & $12(40.0)$ & $\chi^{2}(2)=.66, p>.05$ \\
Science, engineering, and technology & $9(30.0)$ & $12(40.0)$ & \\
Biomedical science & $7(23.3)$ & $6(20.0)$ & \\
Number of years enrolled in higher education & $3.13(1.96)$ & $3.40(1.52)$ & $t(58)=-.59, p>.05$ \\
Mean year of the Bachelor or Master program (SD) & $2.03(1.19)$ & $2.47(1.25)$ & $t(58)=-1.38, p>.05$ \\
Repeated courses higher education (\%) & $13(43.3)$ & $13(43.3)$ & $\chi^{2}(I)=.00, p>.05$ \\
Repeated classes secondary education (\%) & $6(20.0)$ & $2(6.7)$ & $\chi^{2}(1)=2.31, p>.05$ \\
\hline
\end{tabular}

Note. $\mathrm{ARS}=\mathrm{ADHD}$ rating scale; $\mathrm{TDC}=$ typically developing controls.

increase the ecological validity of the experiment. The demographic characteristics and performances of the actors were not included in the results because of their focus on the execution of the script. The other TDC were matched to the students with ADHD on three key variables. This matching procedure is described below.

Students with ADHD were included in the experimental design when (a) they were between 18 and 25 years old, (b) they were enrolled in an institution of higher education during the experiment, and (c) they received an ADHD diagnosis by a psychiatrist or a multidisciplinary team including a psychiatrist because an advice of a psychiatrist is required in Belgium to determine a diagnosis. The diagnosis was validated by the authors by using the ARS (Kooij et al., 2005) and the Diagnostic Interview for ADHD in Adults (Kooij \& Francken, 2010). The diagnosis of all 30 students with ADHD was validated by the use of these diagnostic instruments, and none of the TDC had a clinical or subclinical score on one of the subscales of the ARS. The mean scores on the ARS of students with ADHD and TDC can be found in Table 1. There is an expected significant difference between students with ADHD and TDC on both subscales (inattention and hyperactivity/impulsivity) and on both age categories (childhood and current symptoms).

The students with ADHD also completed the Dutch version of the MINI International Neuropsychiatric Interview (MINI; Sheehan et al., 1998; van Vliet \& de Beurs, 2007) to reveal co-occurring disorders within the psychiatric Diagnostic and Statistical Manual of Mental Disorders (4th ed., text rev.; DSM-IV-TR; APA, 2000) and the International Statistical Classification of Diseases and Related Health Problems (ICD-10; World Health Organization [WHO], 2010). In line with the literature (e.g., Gilbert, 2005; Weyandt \& DuPaul, 2006), the MINI revealed that the majority of students with ADHD $(n=21,70.0 \%)$ were identified as having at least one co-occurring disorder (see Supplemental file 1: Overview of co-occurring disorders).

Of the 75 participating TDC (i.e., 116 participants minus 41 actors), 30 were matched to the 30 students with ADHD based on four demographic characteristics. First, the students with ADHD and TDC were matched based on gender and age. The minority of participating students were male ( $n=10,33.3 \%$ for both groups), and the overall mean age of these students was 21.5 years $(S D=1.87)$. Second, the enrollment in a professional or academic educational program was taken into account in the match. In total, 21 students with ADHD (70.0\%) and 23 TDC (76.7\%) were enrolled in an academic educational program, and 9 students with ADHD (30.0\%) and 7 TDC (23.3\%) were enrolled in a professional educational program. Finally, because of the specificity of each group of educational program (i.e., 1 = Humanities and Social Sciences, $2=$ Science, Engineering, and Technology, and $3=$ Biomedical Sciences), students with ADHD and TDC were matched based on this criterion. Most of the students with ADHD and TDC were enrolled in the group of Humanities and Social Sciences (ADHD: $n=14,46.7 \%$; TDC: $n=12$, 40.0\%) and Science, Engineering, and Technology (ADHD: $n=9,30.0 \%$; TDC: $n=12,40.0 \%$ ), and 7 students with ADHD (23.3\%) and 6 TDC (20.0\%) were enrolled in Biomedical Sciences.

No significant differences were found between the students with ADHD and TDC (see Table 1). The participating students were enrolled in their current institution of higher education for approximately 3 years (ADHD: $M=$ $3.13, S D=1.96$; TDC: $M=3.40, S D=1.52$ ), and they were enrolled in the second or third year of the Bachelor program (ADHD: $M=2.03, S D=1.19$; TDC: $M=2.47$, 
$S D=1.25)$. Last, from the 30 students with ADHD, only $3(10.0 \%)$ never took any medication to treat their ADHD symptoms. Another 19 students with ADHD (63.3\%) always took medication, and 8 students $(26.7 \%)$ only took the medication during examination periods. The students with ADHD were advised to take their medication during the experiment to simulate a real-life examination.

\section{Procedure}

Prior to the study, students with ADHD and TDC received a questionnaire and students with ADHD participated in the MINI and the Diagnostic Interview for ADHD in Adults. The questionnaire was administered online and took about $30 \mathrm{~min}$ to complete. The interviews with the students with ADHD were conducted by the first author and took about $40 \mathrm{~min}$.

Students with ADHD and TDC were invited to participate in the experimental study at one of the available meeting times. The students were scheduled into 14 time slots and were placed together with approximately 10 to 20 other students in an auditorium of an institution of higher education. During the experiment, the participating students had to complete three parallel versions of a paper-and-pencil test. The duration of each of the three tests was unique and counterbalanced, meaning that the order of duration varied for each experiment. In the control condition, students received $1 \mathrm{hr}$; in the first experimental condition, they received 33\% extra time (i.e., $1 \mathrm{hr} 20 \mathrm{~min}$ ); and in the second experimental condition, the students were granted $50 \%$ extra time (i.e., $1 \mathrm{hr} 30 \mathrm{~min}$ ). All participants could not use any extra paper to make notes or calculations. When students finished the test, the supervisor wrote the number of minutes the student needed to complete the test, and the student could take a break before starting the next version. At the end of the third examination, students completed the questionnaire regarding the use of test-taking strategies and their perception during the experimental study and then were rewarded for their participation with a cinema ticket.

Finally, to increase the ecological validity of the experiment, an extra incentive was offered for exceptional performance to increase the stress level and motivation of the participants. Students with ADHD and TDC were informed at the beginning of the experiment that the top performances would be rewarded. Also, three TDC fulfilled the role of actor in each experimental time slot. As mentioned before, these actors received a guideline, which was based on observations of naturalistic examination situations. The supervisor checked whether the actors followed all guidelines correctly and if there were other distractions for the students (e.g., noise from outside the test room). This was noted in the observation scheme. After all participants completed the tests, it was shown that $92.21 \%$ of all manipulations during the experimental study were conducted correctly and on time by the actors.

\section{Measures}

All participating students had to complete an investigatorconstructed questionnaire focusing on demographic details and functioning and participation problems students could experience in higher education. With regard to the demographic characteristics, students had to complete several questions about their educational career in secondary as well as in higher education. The included problems were derived from literature studies with respect to the functioning and participation problems of students with ADHD in higher education (Emmers et al., 2017).

ARS (Kooij et al., 2005). Participants completed this questionnaire of symptoms of inattention and hyperactivity/impulsivity. The ARS consisted of two parts. One part had to be completed to indicate current functioning and the other to reflect functioning of the students in childhood. Each part comprised 25 items. A total of 12 of these items questioned problems related to inattention, and 13 were related to hyperactivity/impulsivity. All items were answered on a 4-point Likert-type scale, ranging from "I never experience this problem" to "I frequently experience this problem."

Diagnostic Interview for ADHD in Adults (Kooij \& Francken, 20I0) and the MINI (Sheehan et al., 1998; Van Vliet, \& De Beurs, 2007). Students who self-reported a diagnosis of ADHD completed the ADHD structured interview, which was used to determine whether ADHD symptoms were present. This diagnostic instrument provided 18 realistic examples, which could be linked to 9 symptom criteria of inattention and 9 symptom criteria of hyperactivity/impulsivity for ADHD. Students with ADHD were asked whether they encountered these problems in childhood and if they were currently experiencing these 18 symptoms (Kooij \& Francken, 2010). The diagnostic interview was based on the Diagnostic and Statistical Manual of Mental Disorders (4th ed.; DSM-IV; APA, 1994) criteria for ADHD. In addition, the MINI was also administered to these students. This is a structured diagnostic interview in which co-occurring psychiatric disorders, as described in DSM-IV-TR (APA, 2000) and the ICD-10 (WHO, 2010), were identified (Van Vliet \& De Beurs, 2007). With concrete yes or no answers, the cooccurring disorders were revealed.

Paper-and-Pencil Tests. Three parallel versions of the paperand-pencil test were created based on data from two pilot studies. The tests comprised three components, namely, arithmetic, matrix reasoning, and comprehensive reading. First, the component arithmetic was inspired by the Wechsler's Intelligence Scale-III (WAIS-III; Wechsler, 1997) and consisted of 12 arithmetic questions. Students with ADHD and TDC had to solve each problem by giving a short answer. Writing any intermediate results was not tolerated. If students with ADHD or TDC wrote down an 
intermediate result, they did not receive any points for their answer, even if it was correct. For each correct answer, students received 1 point, with a maximum of 12 points for each arithmetic component. The second component, matrix reasoning, was also inspired by the WAIS-III and contained 9 items. Students were given 4 possibilities, and they were asked to select the correct answer. The students with ADHD and TDC received 1 point for each correct answer, with a maximum of 9 points for each matrix reasoning component. Third, the comprehensive reading component was based on the Davis Reading Test (DRT; Davis \& Davis, 1962). This test comprised 16 short texts with a different number of multiple-choice questions or items related to the text. Ambiguous items of the DRT that required empathy to solve them, for example, "Which feeling arises when reading this text," were removed to prevent a bias in the results. In total, 21 items of the original DRT were removed. The remaining 42 items were equally divided between the three parallel versions based on the difficulty index of each item. In total, each comprehensive reading component consisted of 14 multiple-choice questions divided over 3 to 5 reading texts. For each question, 5 possible answers were given to the students, and they were asked to indicate the correct answer. Students received 1 point for each correct answer with a maximum of 14 points for each comprehensive reading component. And last, the total score of each student was calculated by adding the points for each component (arithmetic, matrix reasoning, and comprehensive reasoning). All participating students could receive a maximum score of 35 points on each parallel version of the paper-and-pencil test.

Prior to the experiment, 40 (other) TDC were recruited to participate in two pilot studies to develop three forms of equivalent difficulty. The majority of these TDC were female (pilot study $1: n=23,76.7 \%$; pilot study $2: n=8$, $80.0 \%$ ), and the mean age of all students was between 20 and a half and 21 years (pilot study 1: $M=20.93, S D=$ 1.51; pilot study $2: M=20.60, S D=1.90$ ). The students received $1 \mathrm{hr}$ for each of three sets of test questions and were rewarded for their participation after the completion of the third paper-and-pencil test. The sequence of the tests was counterbalanced, meaning that each student received the test in a different order (e.g., student 1: version A-version $\mathrm{B}$-version $\mathrm{C}$; student 2: version B-version A-version C). The paper-and-pencil tests were examined carefully to ensure that the three versions had an equal degree of difficulty and that there were no significant differences between the three versions of the paper-and-pencil test with respect to the average score and the average duration (see Supplemental file 2: Pilot studies).

Questionnaire regarding test-taking strategy and perception on the examination situation. Finally, students who participated in the experimental study were asked to complete a questionnaire regarding the use of test-taking strategy and their perception on the examination situation at the end of the experimental study. The TDC who participated in the pilot studies did not fill in this questionnaire. This investigatorconstructed questionnaire comprised two parts and was based on previous literature (e.g., Cotrell, 2013; Elliott \& Marquart, 2003; Hughes, 2011; Lewandowski, Gathje, Lovett, \& Gordon, 2013; Lewandowski et al., 2015). One part consisted of 15 questions, which had to be answered on a 5 -point scale ranging from $1=$ totally disagree to $5=$ totally agree. This part had to be completed for each test version separately and included questions regarding the test-taking strategy use of students. In the second part, students had to rate 7 questions on a 5-point scale (from $1=$ totally disagree to $5=$ totally agree). Six out of 7 questions were linked to the perception on the examination situation, and 1 questioned the test-taking strategy use of the students during the experiment. After rating each question, the participants were asked to clarify why they agreed or did not agree with the question.

\section{Results}

\section{Counterbalance for Duration}

A significant difference in test scores on the three versions of the paper-and-pencil test was found between two different counterbalanced conditions, namely, the $1 \mathrm{hr} 20-1 \mathrm{hr}-$ $1 \mathrm{hr} 30$ and the $1 \mathrm{hr} 30-1 \mathrm{hr}-1 \mathrm{hr} 20$ counterbalance condition $(M D=28.21, S E=8.05, p<.05)$. This could mean that the performance of students was dependent on the order of the test durations.

\section{Ecological Validity of the Experiment}

Students with ADHD and TDC completed a questionnaire regarding their perception of the examination during the experiment (see Table 3). Both groups of students indicated that the experiment replicated a real-life examination situation. Nonetheless, the students with ADHD and TDC did not experience stress during the experiment (see research question 3).

\section{Research Question I (RQ I): Do Students With ADHD and TDC Use the Extra Time When Receiving Extended Examination Duration?}

The average time students with ADHD and TDC used during the three different conditions is displayed in Table 2. When examining whether students use the extra time, a repeated measure ANOVA was executed. The data indicated that there was a main effect of time, $F(2,116)=11.82, p<$ .001 , meaning that all students used the extra time when receiving extended examination duration. The post hoc Bonferroni correction showed that there was a significant 
Table 2. Mean Test Scores and Duration of Students With ADHD and TDC for the Three Time Conditions.

\begin{tabular}{|c|c|c|}
\hline & ADHD & TDC \\
\hline & $M(S D)$ & $M(S D)$ \\
\hline \multicolumn{3}{|l|}{ I hr (+0\%) } \\
\hline Items correct & 22.77 (4.90) & $24.43(4.29)$ \\
\hline Items attempted & 32.83 (2.59) & 32.87 (3.29) \\
\hline Accuracy (\%) & 69.41 (13.88) & 74.39 (10.52) \\
\hline Duration & $52.93(7.05)$ & $54.13(6.85)$ \\
\hline \multicolumn{3}{|l|}{ I hr $20 \min (+33 \%)$} \\
\hline Items correct & 23.53 (4.95) & $25.03(4.14)$ \\
\hline Items attempted & $33.60(I .8 I)$ & $33.53(2.50)$ \\
\hline Accuracy (\%) & $69.81(12.97)$ & 74.40 (9.39) \\
\hline Duration & $58.17(14.22)$ & $58.87(10.80)$ \\
\hline \multicolumn{3}{|l|}{ I hr $30 \min (+50 \%)$} \\
\hline Items correct & $23.80(5.20)$ & 25.27 (4.59) \\
\hline Items attempted & $33.43(1.96)$ & $34.30(1.06)$ \\
\hline Accuracy (\%) & $70.99(\mid 4.21)$ & 73.52 (12.37) \\
\hline Duration & $61.90(16.45)$ & $60.50(12.08)$ \\
\hline
\end{tabular}

Note. TDC $=$ typically developing controls.

difference between the standard time condition $(+0 \%)$ and the one-third extra time condition $1(+33 \% ; p<.01)$ and the one-half extra time condition $2(+50 \%$; $p<.001)$ but the two experimental conditions did not differ significantly with respect to the time used by the students $(p>.05)$. No main effect of group, $F(1,58)=.01, p>.05$, or interaction effect, $F(2,116)=.37, p>.05$, were found.

\section{Research Question 2 (RQ2): Does the Performance of Students With ADHD Increase More Than the Performance of TDC When Using Extended Examination Duration?}

The number of items answered correctly, the number of items attempted, and accuracy of students with ADHD and TDC in the three time conditions are presented in Table 2. Analyses of the number of items students with ADHD and TDC answered correctly revealed that there were no main effects of duration, $F(2,116)=1.92, p>.05$, nor group, $F(1,58)=2.09, p>.05$, and no interaction effect, $F(1$, $116)=.02, p>.05$, was found regarding the items answered correctly by the students with ADHD and TDC.

No main effect of group, $F(1,58)=.34, p>.05$, nor interaction effect, $F(1.62,94.13)=1.35, p>.05$, were found with respect to the number of items students attempted during the experiment. However, a main effect of duration was uncovered, $F(1.62,94.13)=5.62, p<.01$, and the post hoc test showed that students attempted significantly more items in experimental condition $2(+50 \%)$ compared with the control condition $(+0 \% ; p<.05)$, but there was no significant difference between experimental condition 1 $(+33 \%)$ and the control condition $(+0 \%)$, and between experimental condition $1(+33 \%)$ and experimental condition $2(+50 \%)$.

Finally, when examining the accuracy of students with ADHD and TDC, no main effect of duration, $F(2,116)=$ $.04, p>.05$, nor group, $F(1,58)=2.02, p>.05$, and no interaction effect, $F(2,116)=.55, p>.05$, were uncovered.

\section{Research Question 3 (RQ3): Do Students With ADHD and TDC Alter Their Test- Taking Strategies When Receiving Extended Examination Duration?}

Students with ADHD and TDC answered questions regarding test-taking strategies they used when completing the tests in the three time conditions. Results can be found in Tables 3 and 4. Both students with ADHD and TDC mentioned that they did not alter their test-taking strategy when using extended examination duration (Table 3; overall: $M=$ $2.12, S D=1.29$ ). Furthermore, it became clear that both students with ADHD and TDC completed the tests starting at the beginning and working their way to the end. Other test strategies, such as highlighting important words, starting with the easiest questions, or reading all questions before starting, were not used by the students in the experiment (Table 4).

Nevertheless, some main effects of the test duration were found. First, all students participating in the experiment guessed more items because they ran out of time in the control condition compared with both the experimental conditions, $F(1.44,83.78)=7.79, p<.01$. When comparing the two experimental conditions with a post hoc test, there was no significant difference with respect to number of answers guessed. Second, one overall significant difference was found with respect to working at a slower pace, $F(1.76,101.92)=7.01$, $p<.01$, when receiving extended examination duration. The Bonferroni correction showed that there was a significant difference between the control condition $(+0 \%)$ and the experimental condition $2(+50 \% ; p<.01)$. Both groups of students stated that they continued working the whole time in the control condition, but did not do this in the experimental conditions, $F(2,116)=3.14, p<.05$. When looking at the post hoc test, it was uncovered that the significant difference only existed between the control condition and the experimental condition $2(p<.05)$. Third, all participating students got distracted by the infrastructure more easily when the extra time was given to them, $F(1.49,83.58)=6.18, p<.05$. Post hoc testing using the Bonferroni correction showed that the students were more distracted when comparing the experimental condition 2 with the control condition $(p<.05)$ and with the experimental condition $1(p<.05)$. Here, also, a main effect 
Table 3. Perception on the Examination Situation and the Test-Taking Strategy Use of Students With ADHD and TDC During the Experiment.

\begin{tabular}{|c|c|c|c|c|c|}
\hline & \multirow{2}{*}{$\frac{\mathrm{ADHD}}{\mathrm{M}(\mathrm{SD})}$} & \multirow{2}{*}{$\frac{\text { TDC }}{M(S D)}$} & \multicolumn{3}{|c|}{ Statistics } \\
\hline & & & $t$ & $d f$ & $p$ \\
\hline The experiment replicated a real-life examination. & $3.78(0.81)$ & $3.97(0.81)$ & -.80 & 58 & $>.05$ \\
\hline I was motivated during the experiment. & $4.03(0.85)$ & $4.20(0.61)$ & -.87 & 58 & $>.05$ \\
\hline I needed the extra time to complete the paper-and-pencil tests. & $2.70(1.39)$ & $2.03(1.22)$ & 1.97 & 58 & $=.05$ \\
\hline I felt stressed during the experiment. & $2.80(1.16)$ & $2.07(1.05)$ & 2.57 & 58 & $<.05$ \\
\hline My stress level changed when the experiment evolved. & $3.07(1.23)$ & $2.83(1.26)$ & .73 & 58 & $>.05$ \\
\hline I felt that my performance increased due to the extended time. & $3.15(1.23)$ & $2.57(1.25)$ & 1.87 & 58 & $>.05$ \\
\hline I changed my test-taking strategy in the extended time conditions. & $2.17(1.37)$ & $2.07(1.23)$ & .30 & 58 & $>.05$ \\
\hline
\end{tabular}

Note. TDC $=$ typically developing controls.

Table 4. Test-Taking Strategy Use of Students With ADHD and TDC During the Three Time Conditions.

\begin{tabular}{|c|c|c|c|c|c|c|}
\hline & \multicolumn{3}{|c|}{ ADHD } & \multicolumn{3}{|c|}{ Without } \\
\hline & $\begin{array}{c}\mathrm{TI} \\
M(S D)\end{array}$ & $\begin{array}{c}\mathrm{T} 2 \\
M(S D)\end{array}$ & $\begin{array}{c}\text { T3 } \\
M(S D)\end{array}$ & $\begin{array}{c}\mathrm{TI} \\
M(S D)\end{array}$ & $\begin{array}{c}\mathrm{T} 2 \\
M(S D)\end{array}$ & $\begin{array}{c}\text { T3 } \\
M(S D)\end{array}$ \\
\hline $\begin{array}{l}\text { Filled in the test component by component, } \\
\text { starting at the beginning }\end{array}$ & $3.70(1.37)$ & $3.97(1.19)$ & $3.93(1.26)$ & $3.97(1.25)$ & $4.00(1.02)$ & $4.13(0.97)$ \\
\hline Guessed because I did not know the answer & $2.67(1.35)$ & $2.87(I .3 \mathrm{I})$ & $2.73(1.28)$ & $2.72(1.46)$ & $2.66(1.37)$ & $2.59(1.30)$ \\
\hline Guessed because I ran out of time ${ }^{* *}$ & $1.77(1.25)$ & $\mathrm{I} .43(0.86)$ & $1.37(0.85)$ & $1.97(1.27)$ & $\mathrm{I} .43(0.82)$ & $1.30(0.65)$ \\
\hline Started with the easy questions & $2.67(1.65)$ & $2.83(1.60)$ & $2.90(1.69)$ & $2.97(1.47)$ & $2.80(1.35)$ & $2.73(1.36)$ \\
\hline Marked key words in the questions & $1.40(1.07)$ & $1.43(1.17)$ & $1.40(1.13)$ & $1.47(1.01)$ & $1.40(0.97)$ & $1.63(1.10)$ \\
\hline Worked at a slower pace than usual** & $2.27(1.20)$ & $2.53(1.25)$ & $2.90(1.35)$ & $2.17(1.21)$ & $2.47(1.33)$ & $2.50(1.36)$ \\
\hline First read all the questions before starting & $1.33(0.88)$ & $1.43(0.97)$ & $\mathrm{I} .40(0.93)$ & $1.53(1.17)$ & $1.43(1.01)$ & $1.80(2.01)$ \\
\hline Started with the component that was easiest & $2.03(1.50)$ & $1.97(1.52)$ & $2.00(I .5 I)$ & $\mathrm{I} .77(\mathrm{I} .30)$ & $1.80(1.35)$ & $1.70(1.24)$ \\
\hline Felt motivated during the test & $3.87(0.97)$ & $3.80(0.96)$ & $3.80(0.7 I)$ & $3.83(0.75)$ & $3.83(0.87)$ & $3.87(0.86)$ \\
\hline Felt calm during the test & $3.76(1.06)$ & $3.93(0.96)$ & $4.00(1.10)$ & $4.00(1.04)$ & $4.10(0.98)$ & $4.07(0.96)$ \\
\hline I was distracted visually during the test & $2.73(1.08)$ & $3.00(1.20)$ & $3.03(1.33)$ & $2.67(1.35)$ & $2.57(1.36)$ & $2.63(1.38)$ \\
\hline I was distracted by sounds during the test & $2.90(1.30)$ & $2.83(1.44)$ & $3.10(1.42)$ & $2.33(1.45)$ & $2.37(1.43)$ & $2.37(1.47)$ \\
\hline $\begin{array}{l}\text { I was distracted by the infrastructure during the } \\
\text { test (e.g., squeaking chair, temperature, ....** }\end{array}$ & $2.45(1.30)$ & $2.41(1.32)$ & $2.72(1.39)$ & $1.66(1.01)$ & $1.66(1.01)$ & $1.72(1.10)$ \\
\hline Continued working the whole time* & $4.13(0.94)$ & $3.93(0.83)$ & $3.70(0.95)$ & $4.10(0.84)$ & $4.00(0.98)$ & $4.00(0.98)$ \\
\hline Had problems staying concentrated $* * *$ & $3.20(1.27)$ & $3.23(1.07)$ & $3.57(1.28)$ & $2.40(1.19)$ & $2.20(1.03)$ & $2.30(1.15)$ \\
\hline
\end{tabular}

$*_{p}<.05 . * * p<.005 . * * * p<.001$.

of group was found. Students with ADHD were distracted by the infrastructure more often, $F(1,56)=7.69, p<.05$, than the TDC group. Finally, one main effect of group was found when looking at the item "I had problems sustaining attention," $F(1,58)=15.81, p<.001$. It became clear that students with ADHD had more problems sustaining attention throughout the experiment compared with TDC.

Finally, students with ADHD and TDC were asked about their perception of the examination situation. On average, students with ADHD were neutral when asked whether they needed the extra time to complete the paperand-pencil tests, and those in the TDC group stated that the extra time was not necessary for them, ADHD: $M=2.70$, $S D=1.39$; TDC: $M=2.03, S D=1.22 ; t(58)=1.97$, $p=.05$. In addition, one significant difference was found between the students with ADHD and TDC regarding their stress level during the experiment. TDC reported that they did not feel stressed during the examination while students with ADHD were neutral when asked about their stress level, ADHD: $M=2.80, S D=1.16$; TDC: $M=2.07$, $S D=1.05 ; t(58)=.73, p<.05$. No other significant differences were found between the two participating groups of students with respect to their perception of the examination situation.

\section{Discussion}

This study examined the effectiveness of extended examination duration, which is the most frequently used reasonable accommodation by students with ADHD in higher 
education (Jansen et al., 2017; Kettler, 2012). The literature regarding this topic is very scarce. Therefore, this experimental study was intended to address the following three research questions:

RQ1: Did students with ADHD and TDC use extra time when it was made available?

RQ2: Did the performance of students with ADHD increase more than the test scores of TDC when both groups received extended examination duration?

RQ3: Did students with ADHD and TDC alter their testtaking strategies when receiving extended examination duration?

\section{Use of Extended Time}

The results of the first research question supported the hypothesis that both students with ADHD and the TDC used extra time when it was available, and there were no significant differences between the students with ADHD and TDC. This is in line with the research of Lewandowski and colleagues (2013) who stated that students with ADHD did not differ from students without ADHD regarding the amount of time used during an examination. Regardless of the extra time used, the students never used all the time they were given. It could be assumed that the students with ADHD and/or the TDC worked at a slower pace, and, thus, altered their test-taking strategies when they were granted extended time. Nonetheless, Elliott and Marquart (2003) countered this hypothesis by showing that students with a disability did not work at a slower pace when receiving extra time on a mathematics test. It was possible that the students with ADHD experienced problems related to their diagnosis (e.g., daydreaming, problems with planning and organizing), which made it difficult to finish the examination within the standard time. For example, when the examinations took longer than $1 \mathrm{hr}$, students with ADHD might start daydreaming more, or have more problems with concentration because the amount of time to finish the examination exceeded their ability to stay focused or was long enough and students did not feel any time pressure. Third, it may be that all students, including the TDC, did not have enough time to finish the examination in $1 \mathrm{hr}$, meaning that the paper-and-pencil tests were too time intensive. The time of $1 \mathrm{hr}$ was selected as it was just over the average time taken in the pilot study and would likely lead to variability in the completion rate of participants.

\section{Differential Boost}

To answer the second research question pertaining to the relative increase in items answered correctly by participants in each group, the number of items attempted and the accuracy (i.e., the percentage of correct items) of students with
ADHD and TDC were analyzed. The results revealed that there was no increase in the number of items answered correctly when receiving extended time for both groups of students. This result is not in line with the definition of accommodation that requires a differential boost (Sireci et al., 2005). Sireci and colleagues (2005) stated that if a service does not differentially benefit those with a disability, then it is not addressing the area of impairment, but, instead, simply making a task easier for everyone. In addition, the results of this study contradicted the existing literature where it was suggested that the performance of students with ADHD and/or TDC increased when receiving extended time on a test (Lewandowski, Lovett, Parolin, Gordon, \& Codding, 2007; Lewandowski, Lovett, \& Rogers, 2008; Miller et al., 2015; Sireci et al., 2005). Some found that the test scores of students with ADHD increased evenly compared with TDC (Miller et al., 2015). Others reported that TDC benefited more from the extended examination duration than students with ADHD when these students were under severe time pressure (Lewandowski et al., 2007, 2008). However, the latter research examined the effect of extended examination duration in secondary education, and it is not clear if these results could be transferred to a group of students with ADHD in higher education. Furthermore, the accuracy did not increase in the extended time conditions. These results are consistent with the previous research of Miller and colleagues (2015). Finally, when looking at the number of items students attempted during the different time conditions, it was shown that both students with ADHD and TDC attempted more items in the experimental conditions compared with the control condition. These results are in line with the previous literature where Miller and colleagues (2015) revealed that all students attempted more items when receiving extra time on an examination. In addition, it could be expected that the students altered their test-taking strategies and, for example, had more time to revise all questions and guessed the items that were too difficult for them. This assumption was examined with the third research question.

When looking at the standard deviations of the number of items answered correctly, the number of items attempted, and the accuracy of students with ADHD, it was noticeable that the standard deviations were higher compared with those of the TDC. This might imply that there is a large heterogeneity between the students with ADHD with respect to the objective effectiveness of extended time and that a subgroup of students with ADHD might benefit from the extended examination duration. Although not reported here, further analyses suggested that the results regarding the number of items answered correctly, the number of items attempted, and the accuracy were not altered when comparing male students with female students, low-performing students with ADHD to high-performing students with ADHD, and when taking into account the dyslexia 
diagnosis of the students with ADHD as a covariate. It is possible, however, that the sample size of this study was not sufficiently large to find significant differences between subgroups of students with ADHD. Additional research is necessary to investigate this hypothesis.

In addition, some have argued that the effectiveness of reasonable accommodations is related to the effect of the accommodation on the anxiety and stress level of the students (Elliott \& Marquart, 2003; Lovett \& Leja, 2013). Because the students mentioned that they did not feel stressed or anxious during the experiment, this consideration could not be meaningfully addressed in this study.

\section{Test-Taking Strategies}

Students with ADHD and TDC reported that they did not alter their test-taking strategies during the experiment. They used the same strategies in the control condition and the two experimental conditions. Nonetheless, data revealed that all participating students guessed more items because they ran out of time during the control condition than with extended time. Although the rate of guessing differed between conditions, accuracy did not differ between groups across conditions, suggesting that the effect of guessing was not meaningfully related to performance within group.

All students worked at a slower pace during the experimental conditions. These results contradicted the previous research of Elliott and Marquart (2003) who found that students with a disability did not work at a slower pace when they were granted extended examination duration. This contradiction with the literature could be explained by the suggestion that extended time increases psychological wellbeing and decreases test anxiety for students with a disability (Elliott \& Marquart, 2003). Therefore, it could be expected that the students felt more at ease during the experimental conditions and took their time to finish the tests. These results were partially in line with the previous literature regarding primary and secondary education (e.g., Pariseau et al., 2010). Pariseau and colleagues (2010) suggested that if teachers increased the time pressure, students in secondary education answered more items correctly and, thus, would be more productive. However, this was not the case in our experiment: The number of items attempted increased when receiving extended examination duration, although their performance did not increase (i.e., number of items answered correctly and accuracy).

All students were distracted more by the infrastructure during the extended time conditions compared with the control condition. During the experimental conditions of 1 hr $20 \mathrm{~min}$ and $1 \mathrm{hr} 30 \mathrm{~min}$, students had enough time to finish their test. Hereby, it is expected that students were less focused on completing the test on time and were more distracted by other things going on in the examination room. In addition, the students with ADHD were more distracted by the infrastructure and had more problems sustaining attention during the whole experiment compared with the TDC. This was expected as students with ADHD have difficulties staying focused, or daydreaming more (e.g., Jansen et al., 2017; Weyandt et al., 2013). These results indicated that, despite the medication most of the students with ADHD were taking, this group of students reported having more difficulty concentrating in a testing situation.

It is also noteworthy that students were not using recommended test-taking strategies, such as marking key words, reading all the questions before starting to plan their examination time, or starting with the easy questions. Although these strategies are often recommended, the results of this study suggest that most students see little value in these approaches.

\section{Limitations and Directions for Future Research}

The sample size of this study was small and limited to the types of analyses we could conduct. Thus, only large differences between students with ADHD and TDC could be detected, and important differences may have been missed. Further research should include larger samples to detect small but important differences. In addition, when the sample size is larger, students with ADHD could be divided into subgroups. As suggested by Miller and colleagues (2015), it is possible that the effectiveness of extended examination duration may differ between various subgroups of students (e.g., subtypes, low- vs. high-performing students with ADHD). Also, if the sample size is large enough, it might be possible to compare a group of students with ADHD taking medication with a group of students with ADHD without medication to investigate whether there are significant differences indicating that taking medication can alter the effect of a reasonable accommodation for this group of students. Last, six of the participating students with ADHD also had a co-occurring learning disability, namely, dyslexia. If the sample size is large enough, future research should also examine the difference in effectiveness of the reasonable accommodation when comparing test scores of TDC with students with ADHD, students with ADHD and dyslexia, or students with dyslexia.

The significant difference we reported in the counterbalance suggests caution when interpreting the findings. The significant difference could have been caused by the small number of students $(n=3)$ participating in the counterbalance of the time sequence of $1 \mathrm{hr} 30-1 \mathrm{hr}-1 \mathrm{hr} 20$, and the sample size in the other time sequences was higher. These students were exclusively students with ADHD who obtained lower scores than the average student participating in the study. This imbalance of sample size was due to the matching procedure. As seen in the results, there were no significant differences in the counterbalance of the other time sequences. Future research should take this 
into account and make sure that the sample size of students participating in the six different counterbalanced conditions is equal.

Many of the students with ADHD and TDC completed the paper-and-pencil test within approximately $1 \mathrm{hr}$. Finishing a real-life examination can often take more than $1 \mathrm{hr}$. It is possible that the ADHD-specific functioning problems emerged to a lesser extent during the experimental study compared with a naturalistic examination, or that students with ADHD and TDC felt more tired during a real-life examination in comparison with this simulation. Here, the students were asked to participate in a study that took up to $4 \mathrm{hr}$ and $50 \mathrm{~min}$ (for the three conditions: $1 \mathrm{hr}, 1$ hr 20, $1 \mathrm{hr} 30$ ). As a result, although this study included longer examinations, and, thus, more realistic examinations, than previous research, there are still limitations about the task faced by the participants and the external validity of the procedures.

A high-stakes examination was simulated but important differences between the experimental design and a naturalistic examination situation were present. Although the best performing students received an extra incentive, the students could not obtain credits or did not have to study for the paper-and-pencil test. Because it was not possible to include students with the same background or prior knowledge, the paper-and-pencil test was a generic examination. Prior knowledge was not necessary to participate in the experiment, possibly reducing the mental effort of students with ADHD and TDC. Further research should eliminate this shortcoming by selecting a sample size of students with ADHD and TDC enrolled in the same educational program and with a mutual prior knowledge. This way, study materials can be offered to the participating students to increase the resemblance to a real-life examination and, thus, increase the ecological validity of the test. Also, the students did mention that the design of the examination was a good resemblance of a real-life examination, but the results of the questionnaire also indicated that the students did not feel stressed during the experiment. This lack of stress and fear of failing could impact the results of the experimental study; it is possible that students with ADHD and/or TDC performed better (or worse) during the experiment. Investigators should take this into account when designing a new experimental study. However, it is believed that the right level of stress and anxiety could only be induced by a real-life examination, but this would raise ethical and methodological issues. For example, the equivalence of the difficulty of tests would be challenging, and there are ethical limitations about having students not take advantage of accommodations afforded to them when taking actual tests.

Finally, only one accommodation was examined. Future research should also focus on other accommodations that are perceived to be effective by students with ADHD in higher education (e.g., taking the examination in smaller than usual groups; Jansen et al., 2017). In addition, only students with ADHD were included in the experiment, and accommodations are an important topic of study for students with many types of disorders.

\section{Implications}

The presented study has several (practical) implications. Previous research suggested that both students with ADHD and TDC benefited from extended examination duration, meaning that if only students with ADHD were granted reasonable accommodations, they would have an advantage in comparison with TDC (e.g., Miller et al., 2015). The current study contradicted this assumption. It was shown that the performance of both groups of students did not increase when receiving extra time to complete the paper-and-pencil test. Combined with results from previous studies, the findings from this study further document that extended time does not meet the criteria for being an accommodation for students with ADHD (Harrison et al., 2013). In fact, the evidence suggests that extended time either provides no benefit or simply makes the task easier for everybody. Thus, there are a growing number of studies that suggest that extended time for tests is not an appropriate accommodation for students with ADHD, and consideration should be given to discontinuing it.

Nevertheless, assuming that the reasonable accommodation is not justified or effective for all students with ADHD, in particular, and for students with a disability in general, would be premature as many questions remain. Additional research is warranted. With respect to this study, there was substantial heterogeneity across students with ADHD, which was not found with the TDC. This suggests that there may be subgroups of students with ADHD who respond meaningfully differently from each other in response to extended time, and it is possible that extended time is an appropriate combination for a subset of these students.

And last, these data suggest that students with ADHD and TDC do not use effective test-taking strategies and do not adjust their strategies based on the amount of time they receive to complete a test. Future research should examine whether students with ADHD and TDC do use test-taking strategies and if these cause different results on examinations when they are cued to use these strategies when taking an examination. In addition, focused interventions could be set up for students in higher education and students with ADHD, in particular, to train them to select and implement effective test-taking strategies. Student counselors could coach students in using effective test-taking strategies.

\section{Declaration of Conflicting Interests}

The author(s) declared no potential conflicts of interest with respect to the research, authorship, and/or publication of this article. 


\section{Funding}

The author(s) received no financial support for the research, authorship, and/or publication of this article.

\section{Supplemental Material}

Supplemental material for this article is available online.

\section{References}

American Psychiatric Association. (1994). Diagnostic and statistical manual of mental disorders (4th ed.). Washington, DC: Author.

American Psychiatric Association. (2000). Diagnostic and statistical manual of mental disorders (4th ed., text rev.). Washington, DC: Author.

American Psychiatric Association. (2013). Diagnostic and statistical manual of mental disorders (5th ed.). Arlington, VA: American Psychiatric Publishing.

Barkley, R. A., Fischer, M., Smallish, L., \& Fletcher, K. (2006). Young adult outcome of hyperactive children: Adaptive functioning in major life activities. Journal of the American Academy of Child and Adolescent Psychiatry, 45, 192-202.

Barkley, R. A., \& Murphy, K. R. (2011). The nature of executive function (EF) deficits in daily life activities in adults with ADHD and their relationship to performance on EF tests. Journal of Psychopathology and Behavioral Assessment, 33, 137-158.

Cotrell, S. (2013). The study skills handbook (4th ed.). London, England: Palgrave Macmillan.

Davis, F. B., \& Davis, C. (1962). Davis reading test. San Antonio, TX: Psychological Corporation.

DuPaul, G. J., Weyandt, L. L., O’Dell, S. M., \& Varejao, M. (2009). College students with ADHD: Current status and future directions. Journal of Attention Disorders, 13, 234-250.

Elliott, S. N., \& Marquart, A. M. (2003). Extended time as an accommodation on a standardized mathematics test: An investigation of its effects on scores and perceived consequences for students with varying mathematical skills. Madison: Wisconsin Center for Education Research, University of Wisconsin-Madison.

Emmers, E., Jansen, D., Petry, K., van der Oord, S., \& Baeyens, D. (2017). Functioning and participation of students with ADHD in higher education according to the ICF-framework: A systematic literature review. Journal of Further and Higher Education, 41, 435-447. doi:10.1080/0309877X. 2015.1117600

Gilbert, P. (2005). Attention-Deficit/Hyperactivity Disorder in community college students: A seldom considered factor in academic success. Journal of Social Work in Disability \& Rehabilitation, 4(1/2), 57-75.

Harrison, J. R., Bunford, N., Evans, S. W., \& Owens, J. S. (2013). Educational accommodations for students with behavioral challenges: A systematic review of the literature. Review of Educational Research, 88, 551-597.

Hughes, C. A. (2011). Effective instructional design and delivery of teaching task-specific learning strategies to students with learning disabilities. Focus on Exceptional Children, 44(2), $1-16$.
Jansen, D., Petry, K., Ceulemans, E., van der Oord, S., Noens, I., $\&$ Baeyens, D. (2017). Functioning and participation problems of students with ADHD in higher education: Which reasonable accommodations are effective? European Journal of Special Needs Education, 32, 35-53.

Kettler, R. J. (2012). Testing accommodations: Theory and research to inform practice. International Journal of Disability, Development and Education, 59, 53-66.

Kooij, J. J., Buitelaar, J. K., van der Oord, E. J., Furer, J. W., Rijnders, C. A., \& Hodiamont, P. P. (2005). Internal and external validity of Attention-Deficit Hyperactivity Disorder in a population-based sample of adults. Psychological Medicine, $35,817-827$.

Kooij, J. J., \& Francken, M. H. (2010). Diagnostic Interview for $A D H D$ in Adults version 2.0 (DIVA 2.0). The Hague, The Netherlands: DIVA Foundation. Retrieved from http://www. divacenter.eu/DIVA.aspx

Kuriyan, A. B., Pelham, W. E., Molina, B. S. G., Waschbusch, D. A., Gnagy, E. M., Sibley, M. H., . . Kent, K. M. (2013). Young adult educational and vocational outcomes of children diagnosed with ADHD. Journal of Abnormal Child Psychology, 41, 27-41.

Lewandowski, L., Gathje, R. A., Lovett, B. J., \& Gordon, M. (2013). Test-taking skills in college students with and without ADHD. Journal of Psychoeducational Assessment, 31, 41-52.

Lewandowski, L., Hendricks, K., \& Gordon, M. (2015). Testtaking performance of high school students with ADHD. Journal of Attention Disorders, 19, 27-34.

Lewandowski, L. J., Lovett, B. J., Parolin, R. A., Gordon, M., \& Codding, R. S. (2007). Extended time accommodations and the mathematics performance of students with and without ADHD. Journal of Psychoeducational Assessment, 25, 17-28.

Lewandowski, L. J., Lovett, B. J., \& Rogers, C. L. (2008). Extended time as a testing accommodation for students with reading disabilities: Does a rising tide lift all ships? Journal of Psychoeducational Assessment, 26, 315-324.

Lovett, B. J. (2010). Extended time testing accommodations for students with disabilities: Answers to five fundamental questions. Review of Educational Research, 80, 611-638.

Lovett, B. J., \& Leja, A. M. (2013). Students' perceptions of testing accommodations: What we know, what we need to know, and why it matters. Journal of Applied School Psychology, 29, 72-89.

Meloy, L., Deville, C., \& Frisbie, D. (2002). The effect of a read aloud accommodation on test scores of students with and without a learning disability in reading. Remedial and Special Education, 23, 248-255.

Miller, L. A., Lewandowski, L. J., \& Antshel, K. M. (2015). Effects of extended time for college students with and without ADHD. Journal of Attention Disorders, 19, 678-686.

Pariseau, M. E., Pelham, W. E., Fabiano, G. A., Massetti, G. M., \& Hart, K. C. (2010). Extended time on academic assignments: Does increased time lead to improved performance for children with attention deficit/hyperactivity disorder. School Psychology Quarterly, 25, 236-248.

Schulte, A. A., Elliott, S. N., \& Kratochwill, T. R. (2001). Effects of testing accommodations on students' standardized mathematics test scores: An experimental analysis. School Psychology Review, 30, 527-547. 
Sheehan, D. V., Lecrubier, Y., Sheehan, K. H., Amorim, P., Janavas, J., Weiller, E., . . Dunbar, G. C. (1998). The MINIInternational Neuropsychiatric Interview (M.I.N.I.): The development and validation of a structured diagnostic psychiatric interview for DSM-IV and ICD-10. Journal of Clinical Psychiatry, 59, 22-33.

Sireci, S. G., Scarpati, S. E., \& Li, S. (2005). Test accommodations for students with disabilities: An analysis of the interaction hypothesis. Review of Educational Research, 75, 457-490.

Smith, C. P. (2007). Support services for students with Asperger's syndrome in higher education. College Student Journal, 41, 515-531

Sobanski, E., Bruggemann, D., Alm, B., Kern, S., Philipsen, A., Schmalzreid, H., \& Rietschel, M. (2008). Subtype differences in adults with attention-deficit/hyperactivity disorder (ADHD) with regard to ADHD-symptoms, psychiatric comorbidity and psychosocial adjustment. European Psychiatry, 23, 142-149.

United Nations. (2006, December 13). Convention on the rights of persons with disabilities. Retrieved from http://www.vnverdragwaarmaken.nl/vnverdragwaarmaken/images/vninfo/ VN-Verdragtekst.pdf

University of Leuven. (2015). Annual report 2014-2015. Leuven, Belgium: Author.

van Vliet, I. M., \& de Beurs, E. (2007). Het Mini Internationaal Neuropsychiatrisch Interview [MINI]: Een kort gestructureerd diagnostisch psychiatrisch interview voor DSM-IV-TR en ICD-10-stoornissen (The Mini International Neuropsychiatric Interview [MINI]: a short sctructured diagnostic psyciatric interview for DSM-IV-TR and ICD-10 disorders). Tijdschrift voor Psychiatrie, 49, 393-397.

Wechsler, D. (1997). Wechsler Adult Intelligence Scale-Third Edition (WAIS-III). San Antonio, TX: Harcourt Assessment.

Weyandt, L. L., \& DuPaul, G. J. (2006). ADHD in college students. Journal of Attention Disorders, 10, 9-19.
Weyandt, L. L., DuPaul, G. J., Verdi, G., Rossi, J. S., Scentosky, A. J., Vilardo, B. S., . . . Carson, K. S. (2013). The performance of college students with and without ADHD: Neuropsychological, academic, and psychological functioning. Journal of Psychological Behavioral Assessment, 35, 421-435.

World Health Organization. (2010). International statistical classification of diseases and related health problems, 10th Revision (ICD-10). Geneva, Switzerland: Author.

\section{Author Biographies}

Dorien Jansen is a research fellow at the departmenet of Parenting and Special Education at the University of Leuven and a member of the Leuven Autism Research. She is working on a research project regarding the implementation of reasonable accommodations in higher education.

Katja Petry is an associate professor at the department of Parenting and Special Education at the University of Leuven and specialises in inclusive higher education.

Steven W. Evans, $\mathrm{PhD}$, is a professor in the Department of Psychology at Ohio University and the Co-Director of the Center for Intervention Research in Schools. His work has focused on treatment development and evaluation research for adolescents with ADHD and related disorders.

Ilse Noens is an associate professor at the department of Parenting and Special Education at the University or Leuven. She is a member of the Leuven Autism Research and specialises in ASD throughout the lifespan.

Dieter Baeyens is an associate professor at the department of Parenting and Special Education at the University of Leven and a member of the Leuven Autism Research. He specialises in intervention studies in education and health care in young adults with ADHD or ASD. 